\title{
AS RECENTES REFORMAS EDUCACIONAIS PAULISTAS NA VISÃO DOS PROFESSORES
}

\section{Maria José da Silva Fernandes*}

RESUMO: As reformas educacionais atuais introduziram conceitos econômicos na gestão das escolas e transferiram a responsabilidade pelas ações educativas a seus sujeitos, a quem cabe o sucesso ou o fracasso das mudanças. Nesse contexto, novas formas de controle do trabalho docente passaram a ser utilizadas pelo sistema escolar, tais como as avaliações externas, a imposição de projetos e o pagamento de bônus aos responsáveis pelo trabalho docente. Este artigo resulta de uma pesquisa empírica realizada entre 2006-2008 e visa a apresentar a análise da escola e do trabalho docente a partir do ponto de vista de trinta professores de três diferentes regiões do estado de São Paulo. Os resultados apontam o forte impacto das reformas educacionais e da introdução dos elementos gerencialistas e performáticos no trabalho dos professores, implicando profundas alterações no "ofício" docente, especialmente do professor secundário, o que evidencia um sofrimento ético perante a perda da especificidade histórica do seu trabalho.

Palavras-chave: Reformas Educacionais; Trabalho Docente; Administração Gerencialista.

\section{RECENT EDUCATIONAL REFORMS IN THE STATE OF SÃO PAULO FROM THE TEACHER'S POINT OF VIEW}

ABSTRACT: The reforms, organized and supported by international agencies, reduced the role of the State, introduced economic concepts to school management and delegated the responsibility towards educational actions to the characters responsible for the success or failure of such changes. In this context, new ways of controlling teaching practices started to be used by the school system such as external assessments, imposition of formatted projects by superior bodies and payment of bonus to the education workers. This article results from an empirical research carried out between 2006 and 2008 and is aimed at presenting the analysis of the school and the teaching practices from the point of view of 30 teachers from three different regions of the state of São Paulo. The results show the strong impact of management elements on the teachers' daily practices contributing for their feeling of unease and blame due to the failure of reformed projects. Keywords: Educational Reforms; Teaching Practices; Management.

\footnotetext{
* Doutora em Educação pela Universidade Estadual Paulista Júlio de Mesquita Filho (UNESP) e Professora Assistente no Departamento de Educação da Faculdade de Ciências da Universidade Estadual Paulista Júlio de Mesquita Filho (UNESP. Bauru).E-mail: mjsfer@fc.unesp.br
} 


\section{Introdução}

Este artigo tem o objetivo de apresentar parte dos resultados obtidos por meio de uma pesquisa empírica de base qualitativa que envolveu a realização de entrevistas semiestruturadas com trinta professores do ciclo II do ensino fundamental e do ensino médio da rede pública estadual paulista. Os professores participantes da pesquisa exerciam, no período da coleta dos dados, a docência em nove diferentes cidades pertencentes a três Diretorias Regionais de Ensino localizadas no interior do estado de São Paulo. Os participantes da pesquisa foram selecionados mediante critérios que nos pareceram adequados em relação aos objetivos e ao objeto da pesquisa: os professores deveriam ter mais de dez anos de experiência de trabalho no magistério público paulista; deveriam apresentar comprometimento profissional reconhecido pelos pares e pela comunidade escolar; apresentar diversidade em relação à formação e à disciplina de atuação, e ainda, diversidade em relação ao local de trabalho, sendo que os professores deveriam lecionar em diferentes escolas e, preferencialmente, em diferentes cidades. A opção por essa amostra de professores nos permitiu verificar as semelhanças e singularidades presentes em realidades distintas dentro de uma mesma rede de ensino.

O roteiro utilizado na entrevista semiestruturada apresentava treze questões que se relacionavam a dois temas centrais na pesquisa: $a$ escola pública atual e a atuação da coordenação pedagógica nas escolas. A questão inicial utilizada na entrevista procurou identificar a visão do professor em relação à escola pública paulista em um contexto de reformas educacionais recentes. As respostas apresentadas a essa questão geral serão analisadas e exploradas neste artigo, já que elas nos permitiram construir um panorama geral das escolas nas três diferentes diretorias, sob o ponto de vista dos professores, notadamente no que se referia à implantação das sucessivas reformas educacionais a partir do final do século XX. 


\section{As escolas públicas estaduais paulistas e as reformas educacionais recentes}

A década de 1990 e os anos iniciais do século XXI foram marcados por reformas educacionais que alteraram profundamente as condições de funcionamento das escolas em diferentes partes do mundo. Negligenciando as diferenças entre os sistemas de ensino e suas unidades escolares e utilizando matrizes reformistas definidas unilateralmente pelos organismos internacionais, matrizes essas norteadas por princípios gerencialistas e performáticos, as reformas educacionais recentes introduziram amplas mudanças na organização das escolas e no trabalho de seus sujeitos. No estado de São Paulo, a situação não foi diferente. $\mathrm{Na}$ segunda metade da década de 1990, a partir da chamada "Escola de Cara Nova" (SÃO PAULO, 1996), a Secretaria da Educação iniciou um amplo projeto de reforma educacional que, ao utilizar uma estratégia política de transformação técnico-estrutural, atingiu todos os professores e alunos da rede estadual de ensino.

A denominação atribuída ao conjunto de elementos que compunha essa reforma era muito sugestiva. A "Escola de Cara Nova" implicava uma transformação total na organização educativa, como se fosse possível mudar totalmente um cenário preexistente para a implantação de um novo modelo educacional. Ball (2004) afirmou que havia, no contexto mundial, a necessidade de reinventar a educação, em consonância com a reinvenção do governo. Para o autor, esse foi um dos pontos de partida da nova ortodoxia que dominou a economia e a política na última década. Nesse sentido, essa interpretação coincidiu com o movimento que ocorreu em meados da década de 1990 com o governo paulista e a implantação de novas medidas em todos os setores sociais e administrativos, medidas essas que ficaram conhecidas como "choque de gestão".

Vinda de surpresa, a "Escola de Cara Nova" conseguiu cumprir seus objetivos, ao menos aqueles estabelecidos sob o ponto de vista institucional e oficial. A partir de sua implantação, o pacote reformista deu origem a uma série de alterações pedagógicas, administrativas e de gestão dos recursos financeiros na rede estadual de ensino. Em nenhuma outra ocasião, a educação paulista conhecera um pacote de medidas tão articuladas e capazes de alterar substancialmente as escolas como o que se apresentou naquele momento. Os elementos iniciais da reforma começaram a ser 
apresentados oficialmente em 1995 e, nos anos seguintes, outros elementos complementares surgiram para consolidar uma reforma muito bemarticulada do ponto de vista da implementação. Nada ocorreu por acaso e de maneira desarticulada nas escolas.

Com a reforma vieram, por exemplo, a adequação do fluxo escolar e as classes de aceleração que anteciparam o estabelecimento do regime de progressão continuada, os ciclos de aprendizagem e a recuperação de férias. Houve a reorganização da rede física escolar em função dos ciclos de ensino, abrindo caminho para a futura municipalização do ensino das séries iniciais, bem como a implantação de telessalas para atendimento dos alunos mais velhos e a consequente redução do ensino supletivo regular. Tudo isso justificado pela defesa da melhoria da qualidade do ensino, que passou a ser avaliado, a partir de 1996, pelo Sistema de Avaliação do Rendimento Escolar do Estado de São Paulo (SARESP).

A reforma e suas novas medidas trouxeram novas exigências às escolas e a seus sujeitos que passaram, a partir daquele momento, a se empenhar no fortalecimento da relação com a comunidade através do estabelecimento de parcerias, da atuação de ONGs e dos "Amigos da Escola". Essas novas relações se articularam a outras medidas, como a descentralização das verbas garantidas com o repasse direto de recursos às Associações de Pais e Mestres (APMs) e a elaboração do Plano de Gestão da Escola. Também fizeram parte da reforma a criação das salasambientes, a flexibilização curricular do ensino médio e os projetos de desenvolvimento de lideranças educacionais que, posteriormente, foram acompanhados pela implantação do bônus-mérito, que veio atrelado a medidas quantitativas de avaliação das escolas e de seus professores.

As medidas que chegaram até as escolas nesse período não incluíram a participação dos professores, movimento contrário ao que havia ocorrido na década de 1980, quando houve fortalecimento da categoria docente e do movimento sindical nos processos decisórios ${ }^{2}$. Contrariamente a esse movimento de democratização das decisões e de fortalecimento do coletivo, a "Escola de Cara Nova" se impôs em uma lógica vertical, em que as medidas definidas por técnicos e especialistas nas esferas centrais do governo chegaram às escolas sem a participação efetiva dos professores. As decisões sobre as reformas educacionais foram conhecidas pelos professores por meio das publicações oficiais que chegaram até as escolas, tais como os livretos que tinham a mesma denomi- 
nação da reforma - Escola de Cara Nova - e que continham informações sobre as salas-ambientes, a progressão continuada, a recuperação de férias, etc. Essas publicações apresentavam uma retórica discursiva apurada, embora muitas vezes paradoxal em função do "hibridismo" da reforma (BARROSO, 2006), que, por exemplo, defendia, em um mesmo documento, a necessária autonomia das escolas e, por outro lado, a sua regulação por meio das avaliações externas. O discurso reformista também procurava convencer docentes e comunidade escolar da necessidade das novas mudanças, utilizando, para isso, algumas bandeiras progressistas, tais como a democratização da gestão, a valorização da escola como lócus da formação docente, a importância do trabalho coletivo e da autonomia das escolas, entre outras que, desde a década de 80, compunham as reivindicações docentes. No entanto, as reformas dos anos 1990 utilizaram essas bandeiras como instrumentos para defesa de seus projetos e, não raramente, para justificar a minimização do papel do Estado em relação a suas obrigações sociais históricas.

Em 2002, alguns anos depois da reforma inicial, e sob a pressão de uma nova eleição para governador, a "Escola de Cara Nova" já estava praticamente consolidada, embora as "metas de produtividade" não se apresentassem de forma satisfatória nas avaliações oficiais. Além de os resultados nas avaliações externas, principalmente no SARESP, apontarem que o rendimento dos alunos estava aquém do esperado, também alguns resultados de pesquisas realizadas nas escolas paulistas teciam críticas às reformas educacionais e a seus impactos no cotidiano (DIAS-DASILVA，2001; DIAS-DA-SILVA; LOURENCETTI， 2002; MARIN; GUARNIERI, 2002; FALSARELLA, 2002; GUILHERME, 2002; MARTINS, 2001), tais como a ampliação da rotatividade e da itinerância, a falta de condições adequadas de trabalho e a ausência do professorado nas decisões tomadas.

Assim, em 2002, ano de eleição para governador, algumas propostas da "Escola de Cara Nova" começaram a ser diluídas, em função da substituição da secretária estadual de educação. Sem muitas explicações, a secretária Rose Neubauer, considerada intransigente pelas forças sindicais e pela imensa maioria dos professores, foi substituída por um novo secretário. No entanto, pode-se dizer que se para o governo paulista o "caminho" já estava pavimentado para a implantação de novas medidas, às escolas faltava ainda o "chão" perdido com as mudanças anteriores. 
As medidas lançadas pelo novo secretário foram tão eficientes quanto a "Escola de Cara Nova" na desestruturação da cultura escolar e do ofício dos professores. A "Escola do Acolhimento", denominação dada ao novo pacote de reformas educacionais, pregava a melhoria das relações interpessoais entre alunos e professores, o desenvolvimento da cidadania e o protagonismo juvenil. Algumas medidas implantadas pela secretária anterior, tais como a recuperação nas férias, a flexibilização curricular do ensino médio e as salas-ambientes, foram extintas, e outras foram agregadas ao pacote original. Entre as novas medidas que chegaram às escolas merecem destaque o Programa Escola da Família, Projeto Escola da Juventude, Ensino Médio em Rede, Programa de Formação de Professores "Teia do Saber", além da aproximação da Secretaria com as Diretorias Regionais por meio de "capacitações" videoconferências. As transformações ocorridas não foram pequenas. Houve clara preocupação oficial com a exposição midiática, com os projetos realizados pelos professores, normalmente pontuais, "empacotados" e desconectados das condições de trabalho, e excessiva ênfase no papel socializador das escolas, refletido em uma pretensa proposta de "escola do acolhimento" em substituição à "escola do conhecimento".

As novas medidas, implantadas entre 2002 e 2006, intensificaram a presença dos elementos da gestão gerencialista e performática no interior das escolas públicas paulistas. A já iniciada política de avaliação do desempenho das escolas e dos professores, que havia sido implementada por Rose Neubauer, foi intensificada. Expressões como bônus mérito, avaliação de desempenho, desempenho profissional e avaliação externa passaram a fazer parte do cotidiano dos professores e a definir padrões de conduta e de trabalho dentro das escolas. A performatividade passou a pautar a definição de currículos, projetos e até a própria formação dos professores na rede estadual. O "Estado Avaliador" (SANTOS, 2004; CORREIA; MATOS, 2001) ou "Regulador" (BARROSO, 2006), que gradativamente foi ocupando o lugar do "Estado Educador", apresentou grande preocupação em relação à publicação de informações e indicadores, além do estabelecimento de um caráter julgador e comparativo em relação às escolas (BALL, 2005; BIRGIN, 2000). Para Ball (2005, p. 545), essas novas formas de avaliação das escolas são denominadas pedagogias invisíveis de gerenciamento, que, "por meio de avaliações, análises e formas de pagamento relacionadas com o desempenho, 'ampliam' o que pode ser controlado na esfera administrativa'. 
As medidas gerencialistas e performáticas adotadas pelos sucessivos governos paulistas contribuíram para alterar profundamente a realidade escolar, no início do século XXI, ampliando a angústia e o descontentamento dos professores. Da "Escola de Cara Nova" e da "Escola do Acolhimento" e seus impactos iniciais no cotidiano das escolas, passou-se mais de uma década. Apesar da permanência de um mesmo partido político no poder e do predomínio do direcionamento neoliberal, diferentes secretários passaram pela pasta da Educação, que, de maneira geral, apresentou diferentes projetos às escolas, reafirmando a já conhecida descontinuidade política. A cada secretário, uma mudança e, antes mesmo de serem discutidas e avaliadas as medidas implantadas, elas já eram substituídas por outras, negligenciando-se continuamente a escola e seus sujeitos. Nesse sentido, Almeida (2006, p. 87) afirmou que a descontinuidade nas políticas é mais uma das características das reformas educacionais atuais que "não aprofundam a avaliação do que foi implementado e, com bastante freqüência, pautam-se por inaugurar uma nova medida que tenha a marca da gestão atual. Com isso repetem-se erros, desperdiçam-se recursos, desfaz-se do esforço empreendido pelas equipes escolares".

Em 2008, depois de os indicadores avaliativos - ENEN, PISA e SARESP - publicizarem o fracasso do ensino público paulista e, portanto, do modelo educacional adotado há mais de uma década, "São Paulo faz escola" foi o novo jargão utilizado para as medidas centralizadoras e reformistas que, desde então, tem chegado até as escolas. Novas relações de hierarquia, procedimentos de motivação e mecanismos de reformação chegaram às escolas, cujos sujeitos ganharam outra dimensão. Uma dimensão assentada, cada vez mais, no trabalho individual, em detrimento do coletivo, bem como na centralização das medidas e no contínuo controle, por meio das avaliações externas. Diante de tantas mudanças que continuaram a negar a "voz" dos professores, como eles avaliaram os impactos das sucessivas reformas nas escolas paulistas? 


\section{A "voz" dos professores sobre as escolas públicas estaduais paulistas em um contexto de reformas educacionais}

Os professores participantes desta pesquisa, apesar de trabalharem em diferentes contextos e cidades, apresentaram uma visão sobre a escola pública paulista bastante coincidente, o que nos levou a afirmar que a implantação vertical das reformas trouxe grandes impactos ao trabalho docente, independentemente do local em que se realizava a docência. A escola mudou muito nos últimos anos do século XX e no início do século XXI e tem sido difícil a relação dos professores com essas mudanças. Tal fato foi tristemente denunciado pelos professores participantes da pesquisa, mas é importante ressaltar que esses sujeitos não tinham uma visão saudosista da escola excludente que outrora existiu. Eles analisaram a escola e as mudanças que nela ocorreram de maneira contextualizada e afirmaram, categoricamente, que sentiam falta de uma escola que pudesse ensinar a todos, de uma escola democrática, em que alunos e professores fossem, de fato, sujeitos.

Por encararmos os professores como sujeitos e por considerarmos a negligência das reformas educacionais atuais em relação aos docentes é que os colocamos no centro das discussões sobre o cotidiano escolar e suas transformações. Aproximadamente 50\% dos participantes da pesquisa manifestaram-se em relação ao fato de não terem "voz", de não serem sujeitos na elaboração das propostas que são implantadas nas escolas. Muitos deles se referiam a isso afirmando: "Ninguém ouve o professor, as coisas chegam na escola, agora é assim, vocês vão fazer assim"4 (P $\left.1^{5}\right)$. A não-participação nas esferas decisórias da educação foi muito criticada por eles, assim como a culpabilização a que eles têm sido submetidos quando as medidas que chegam até as escolas não saem a contento: "Todo mundo se acha no direito de falar da educação, de achar que a educação vai mal e que o único culpado é o professor, que o único a ser crucificado é o professor" (P 4). Acusados, muitas vezes, de resistentes às mudanças, os professores demonstraram não que aceitavam com tranquilidade a imposição das medidas que, por desconhecimento ou estratégia, ignoravam a realidade escolar.

As escolas em que os professores investigados trabalhavam eram influenciadas pela retórica reformista que, ao mesmo tempo em que exortava a participação dos professores, não lhes permitia opinar na definição 
das propostas. Esse contexto contraditório foi evidenciado nas entrevistas, como podemos ver na resposta de um dos professores, ao questionar a apregoada autonomia, tão presente nos documentos legais e nos discursos reformistas e, ao mesmo tempo, tão distante da realidade das escolas: "A gente vive um momento educacional em que a palavra autonomia é muito contraditória porque ao mesmo tempo que a gente chega a imaginar que a escola pode, de alguma forma, decidir algumas coisas, há, muitas vezes, muitas medidas, que chegam sem a participação de ninguém" ( $\mathrm{P}$ 24).

A difícil relação dos professores com as reformas que desestruturam a cultura escolar provocaram situações de angústia e até mesmo de adoecimento entre os docentes. Vinte dos entrevistados (aproximadamente $67 \%$ dos professores), em diversos momentos, se referiram ao trabalho realizado nas escolas utilizando expressões como angústia, sofrimento, frustração, irritação e, em alguns casos, não se esforçaram em conter as lágrimas ou esconder a emoção que se juntava às palavras. Outros pesquisadores, em diferentes contextos, já haviam se debruçado especificamente sobre a relação trabalho docente/saúde (ESTEVE, 1999; CODO, 2000; ASSUNÇÃO, 2003). A ocorrência de problemas de saúde gerada pelas condições de trabalho adversas pode provocar o abandono da profissão e, o que é muito comum, o desinvestimento e o desânimo em relação ao trabalho cotidiano. Tal situação foi manifestada por nossos entrevistados, como uma professora que afirmou: "Vai lá e vê quantos professores estão com depressão, quantos professores estão de licença, quantos estão estafados. A situação está deixando todo mundo doente" (P 3). Nesse contexto de reformas, os professores se sentiam culpados pelo fracasso das medidas e assumiam as falhas sistêmicas como sendo falhas pessoais, o que, com frequência, provocava um índice de stress bastante elevado, como nos afirmou Santos (2004).

Os sentimentos de angústia, de sofrimento e de perda estiveram presentes na fala dos professores, que estavam fortemente impactados pela "cultura do desempenho", pela introdução da performatividade nas escolas, que, no caso dos docentes, se expressava sob a forma do "bônus mérito". O bônus mérito foi instituído pela Secretaria de Estado da Educação no início deste século, constituindo-se em um abono anualmente pago aos professores e demais profissionais das escolas. $\mathrm{O}$ valor pago se baseava, até o início de 2009, em critérios quantitativos, tais como a fre- 
quência dos professores nas aulas, o número de projetos realizados, o desempenho nas avaliações externas e as taxas de evasão e repetência. Apesar de considerar, principalmente, os elementos quantitativos relativos à escola como um todo, o bônus se constituía em um valor pago individualmente aos professores, fazendo com que os créditos recebidos tivessem uma variação considerável dentro das escolas.

Reconhecemos o bônus como um mecanismo de performatividade, tão ao gosto das políticas de cunho neoliberal. Ball (2004) já afirmava que a performatividade facilitava "o papel de monitoramento do Estado, que governa à distância - governando sem governo". Nesse sentido, o ensino passava a seguir regras que permitiam atingir metas determinadas de maneira exógena, o que alterava, profundamente, a relação do professor consigo mesmo e com seu próprio trabalho: "os professores são representados e encorajados a reflectir sobre si próprios como indivíduos, que fazem cálculos sobre si próprios, 'acrescentam valor' a si próprios, aumentam a sua produtividade, vivem uma existência baseada em cálculos" (BALL, 2002, p. 5-6). A influência do bônus foi fortemente relatada pelos professores, dezoito entrevistados ${ }^{6}$ (o que correspondeu a mais da metade dos participantes) se referiram aos efeitos desse mecanismo nas mudanças de comportamento dos professores e no trabalho das escolas, como afirmou uma professora: "é ele (o bônus) que dita as coisas agora dentro da escola" (P 5). Ball (2002) afirmou que o pagamento por produtividade era um indicador claro das pressões para fazer dos sujeitos e das escolas "empresas" que passaram a viver e a trabalhar em função de cálculos, estabelecendo uma relação pragmática e de alto valor performático.

Uma das críticas ao bônus que foi apontada pelos entrevistados se referiu ao caráter individualizante de sucesso que foi invadindo as escolas nos últimos anos (LÜDKE; BOING, 2004; SAMPAIO; MARIN, 2004; BALL, 2002; 2004; SHIROMA; CAMPOS, 2006), transferindo para o professor a resolução de problemas de ordem estrutural. Assim, o sucesso do trabalho do professor nas unidades escolares deveria ser quase exclusivamente uma responsabilidade individual, cabendo aos docentes empreendedorismo, criatividade, confiança e disposição para a realização satisfatória do trabalho docente. $\mathrm{O}$ individualismo fortalecido pela introdução do bônus nas escolas foi alvo de críticas pelos professores: "O bônus reflete as condições da sociedade neoliberal, uma sociedade extre- 
mamente individualista. O bônus levou os professores a ficarem se comparando, querendo saber quanto o outro recebeu, quantas faltas o outro deu, vira um clima policialesco" (P 7).

Durante as entrevistas, os professores deixaram evidente a força, a pressão, que esse mecanismo adquiriu dentro da rede pública paulista de ensino, força esta capaz de alterar profundamente a organização do trabalho e a prática dos professores em sala de aula: "A pressão é muito grande e cai principalmente lá embaixo, em nós os professores, e não adianta dizer que as pessoas não estão preocupadas com o financeiro porque elas precisam de dinheiro para viver" (P 7). Outros apontaram o caráter contraditório do bônus, que, ao mesmo tempo que dava "prêmios", provocava a alienação e o desânimo perante a incapacidade do professor de se sentir sujeito de seu próprio trabalho e de se mobilizar para exigir mudanças, como por exemplo: "O bônus destruiu a capacidade de mobilização, destruiu o professor como sujeito formador e está destruindo o professor como pessoa, como sujeito, porque cria uma alienação, uma dependência. Ele não se reconhece mais como sujeito, ele perde o ânimo" (P 20).

A análise que os professores realizaram em relação ao bônus foi ao encontro da interpretação de Ball (2004, p. 1116) sobre o papel da performatividade nas instituições, sendo capaz de alterá-las significativamente, assim como o trabalho dos professores. Para esse autor, a performatividade tem produzido novos perfis de trabalhadores, objetivando e mercantilizando o trabalho docente, que se transformou em resultados, níveis de desempenho, formas de qualidade. Shiroma e Campos (2006, p. 227) também apontaram referências ao caráter contraditório da administração gerencialista, que, ao mesmo tempo que utilizava uma retórica voltada para as novas práticas de trabalho em equipe, estimulava a competição e a desigualdade entre os pares. Para as autoras, as novas formas de controle do trabalho docente levaram ao cultivo de sentimentos ambíguos nas unidades escolares, na medida em que o trabalho passou a subordinar-se a relações contraditórias de cooperação/competição, em que os professores, ao mesmo tempo que precisavam dos demais, também competiam uns contra os outros.

O bônus, além da pressão individual exercida sobre os professores, também contribuiu para o refluxo das atividades sindicais, contrariamente à década de 1980, em que a categoria mostrou uma forte capacidade de mobilização política e de reivindicação pela democratização do ensi- 
no e por melhores condições de salários e de trabalho (DIAS-DA-SILVA; FERNANDES, 2006; OLIVEIRA, 2006; ZIBAS, 1997). A individualização do processo de ensino e a introdução de novas formas de controle "empresarial" nas escolas reduziram a capacidade de mobilização e de solidariedade baseadas em uma identidade profissional comum (BALL, 2002). Assim, foram reduzidas as práticas de filiação a sindicatos, levando ao enfraquecimento dos movimentos reivindicatórios e à segmentação da categoria docente (SHIROMA; EVANGELISTA, 2003).

A preocupação com o bônus se transformou em elemento central no interior das escolas e, de acordo com nossos entrevistados, passou a pautar o que deveria e o que não deveria ser feito pelos professores. A preocupação com os dados que eram encaminhados para os órgãos centrais e, posteriormente, incorporados aos valores financeiros passou a se sobrepor ao papel clássico da escola em relação ao ensinar e aprender. A performatividade "encoraja as instituições a se preocuparem cada vez mais com seu estilo, sua imagem, sua semiótica, com a maneira como apresentam as coisas mais do que como as fazem funcionar" (BALL, 2004, p. 1117).

Assim, a escola pública paulista se transformou, utilizando as palavras de uma professora entrevistada, na "escola do espetáculo". Nela, era importante apresentar indicadores positivos, mesmo que eles não correspondessem à realidade ou ao papel que deveria ser de fato exercido pelas instituições. $\mathrm{Na}$ "escola do espetáculo" era importante desenvolver projetos, mesmo que eles substituíssem os conteúdos que historicamente eram trabalhados na educação básica. Era importante assumir papéis sociais que anteriormente não cabiam às escolas. Foram tantas as "prioridades" impostas às escolas que elas colocaram em risco o "ofício" do professor, outro motivo de angústia dos docentes participantes da pesquisa. Os professores reclamaram categoricamente da pressão sofrida para que a escola "esteja bem na fita" (P 10), mesmo que isso significasse menor preocupação com a qualidade do ensino oferecido às crianças e aos jovens. A "educação de verniz" (P 14) citada por uma professora parece estar contribuindo para a proliferação de alunos "sidão", expressão utilizada por Dias-da-Silva (2001) para se referir aos muitos alunos que estavam concluindo os estudos sem sequer saber ler e escrever.

Em nome de uma socialização exagerada, os professores assumiram cada vez mais papéis que acarretaram sobrecarga de tarefas a um tra- 
balho já bastante difícil e exigente. Oliveira (2003; 2004), Lourencetti (2004) e Almeida (2006) já haviam apontado a sobrecarga de tarefas a que os professores estavam submetidos, dados confirmados pelas entrevistas quando os professores alegaram tratar em sala de aula de temas relacionados a gravidez na adolescência, dengue e problemas ambientais até a economia de energia e outros. "Tudo vem para a escola, ela tem que resolver todos os problemas", afirmou uma professora. A sobrecarga de tarefas também foi uma das causas da insatisfação dos professores com o trabalho nas escolas, fato também apontado por Oliveira (2003, p. 34), ao afirmar que os docentes se veem forçados a dominar práticas e saberes antes desnecessários ao exercício de suas funções.

Muitas das novas tarefas desenvolvidas pelas escolas se deram sob a forma de "projetos", prática que se tornou comum nas escolas paulistas, inclusive pela gratificação pressuposta no "bônus mérito". É importante salientar que, quando questionados sobre a proposta da Secretaria da Educação em relação aos projetos, os professores foram unânimes: todos reclamaram do excesso desse tipo de atividade e da improvisação com que ela normalmente ocorria nas escolas. Além disso, os professores afirmaram que, muitas vezes, realizavam os projetos por força da presença dos mecanismos de pressão e de cobrança. Os projetos realizados eram, normalmente, pontuais, descontextualizados do conteúdo desenvolvido pelo professor em sala de aula e ligados à defesa dos métodos ativos e do protagonismo juvenil. Para Zibas (2005), esse tipo de proposta minimizava o ensino de conteúdos e, quando realizados em condições de trabalho adversas, não atingiam os resultados esperados.

As críticas aos "projetos" foram muito presentes nas entrevistas. Entretanto, ressaltamos que os professores não eram contrários às inovações, às novas práticas de trabalho e de organização curricular, o que eles rejeitavam eram as imposições e os projetos formatados de cima para baixo, que desconsideravam as condições e necessidades reais das escolas: "Os projetos são complicados porque virou uma coisa de só fazer projetos (...). É preciso analisar os projetos, principalmente aqueles que chegam para a escola, e ver a viabilidade deles, ver se é bom ou não para a escola naquele momento" (P 5). Outra crítica que os professores apresentaram aos projetos se referiu à ausência de avaliação do trabalho realizado em sala de aula, que transformava a prática em algo mecânico, em simples tarefa que deveria ser cumprida e computada para o recebimento do 
bônus: "Os projetos são impostos, veio de lá e tem que fazer e mostrar o serviço. Também não tem avaliação, não se discute o que deu certo, o que não funcionou, porque não funcionou. É fazer por fazer. É fazer por que conta no bônus. Não está certo!” (P 15).

É importante ressaltar que, por outro lado, os professores entrevistados avaliaram positivamente os projetos ${ }^{7}$ que nasciam na escola, que eram frutos de tentativas de coletivização do trabalho: "Eu sinto que esses projetos da escola têm uma adesão maior dos alunos do que os projetos que são impostos. É água, lixo, energia elétrica, eles estão sendo repetitivos. Os projetos que brotam da escola são muito mais ricos que aqueles que são formatados pela DE” (P 23).

Além da imposição, a preocupação com a minimização dos conteúdos escolares subjacentes aos "projetos" desenvolvidos, que ocorreu a reboque de uma "nova" maneira de trabalhar, foi explicitada no discurso dos professores. Semelhante a Sampaio e Marin (2004), que questionaram os projetos tão presentes nas escolas e o "empobrecimento do processo pedagógico", que, muitas vezes, acabava por ocorrer quando as escolas optavam por organizar o currículo de maneira diferenciada, mais da metade dos professores entrevistados denunciou o risco do abandono dos conhecimentos escolares clássicos pela escola. Isso não significou a defesa, pelos professores, da escola conteudista baseada na memorização. Eles defenderam o direito dos alunos aprenderem, de se apropriarem de conhecimentos básicos, o que significava, entre outras coisas, saber ler e escrever e realizar cálculos básicos corretamente, como expressaram os professores a seguir: "Eu não chego a ser rígida demais na defesa de que a escola tem que ser conteudista, mas eu não defendo essa coisa que está aí de não dar mais nenhum valor ao conteúdo" (P 8) ou, ainda, "Projeto é importante, mas e o conteúdo? As crianças estão sem saber ler e escrever... é só em cima de projetos e o conteúdo mesmo... Projeto é importante, mas não é tudo!"' (P 13).

Historicamente, o ofício do professor secundário se assentou na especificidade dos conteúdos, na transmissão cultural, o que entrou em crise na maneira como se estruturou a escola no contexto das reformas atuais (DIAS-DA-SILVA, 2001; LÜDKE; BOING, 2004; LOURENCETTI, 2004). Sampaio e Marin (2004) apontaram também a fragilização da função disciplinadora e de controle, que, anteriormente, compunham o trabalho do professor e que foram postos em xeque na organização do cur- 
rículo com base em projetos. Correia e Matos (2001), ao analisarem o contexto português, referiram-se também à perda do poder dos professores, que, anteriormente, se assentava em uma delegação cognitiva muito evidente: os professores eram depositários do saber científico. A perda dessa especificidade do trabalho docente secundário tirou o "chão" dos professores. Uma professora de matemática entrevistada mostrou-se indignada com o fato de a escola ter perdido sua dimensão clássica na transmissão dos conteúdos historicamente acumulados: "A escola é o local do conhecimento acadêmico (...), principalmente para quem não pode buscá-lo em outros lugares, é para isso que as escolas existem. Escola não é só circo, só oba-oba. Eu não quero dizer com isso que sou contra a solidariedade, contra a arrecadação de agasalhos, mas tem hora pra tudo..." (P 3).

A preocupação com o que a escola estava ensinando também se fez presente na fala de uma professora que associou a minimização dos conteúdos à ampliação das responsabilidades assumidas pela escola atual: "Eu acho que a escola está deixando de cumprir o seu papel na sociedade como produtora do conhecimento, a escola não está fazendo a parte dela, ela não está ensinando. A escola abarcou a família, a comunidade, e o cerne da escola que é o saber está sendo de verniz, está sendo superficial" (P 14). Moraes (2003, p. 152-153) afirmou que, nos últimos anos, a educação foi tomada por um forte pragmatismo, o que, em nossa opinião, se expressou, nas escolas de ensino básico, sob a forma de projetos, levando a um recuo da teoria, que passou a ser vista como perda de tempo. No entanto, foi assim que os professores ensinaram por muitos anos e ainda é assim que eles sabem ensinar, daí o sentimento de perda e, às vezes, até de culpa, que acompanhou a imposição das mudanças atuais.

É importante apontar que a pressão pela realização de projetos se deu em um contexto profissional em que as condições de trabalho não foram modificadas para garantir que as inovações fossem realizadas com sucesso. A escola e suas condições permaneceram iguais, mas as exigências feitas aos docentes foram grandiosas. Esse fato foi lembrado por um professor ao se referir à falta de sensibilidade dos órgãos externos para lidar com a situação: "É preciso ter sensibilidade para entender que trabalhar com projetos exige condições materiais, que trabalhar com projetos interdisciplinares exige uma condição profissional que nós estamos muito distantes. O projeto, do ponto de vista pedagógico, pressupõe melhorias na qualidade do trabalho (...)" (P 24). 
Os professores entrevistados centraram suas críticas no impacto das reformas no trabalho docente, ou seja, as reformas alteraram o trabalho nas escolas, mas não as condições para a realização do mesmo. Aproximadamente $70 \%$ dos professores criticaram os baixos salários, o acúmulo de tarefas, a ausência de tempo para o planejamento do trabalho e para a organização do coletivo nas escolas. Como trabalhar de maneira diferente dentro de condições tão adversas? Para trabalhar com projetos pedagógicos de maneira séria e comprometida eram exigidas condições de estudo e aprimoramento contínuo. $\mathrm{O}$ acesso dos professores a informações, leituras e aquisição de um capital cultural mais amplo tem sido bastante limitado, principalmente se considerarmos as condições de trabalho a que eles foram submetidos e os baixos salários recebidos, como apontou o professor a seguir: "Como esse professor tem acesso à cultura em um país em que um livro custa em média $R \$ 50,00$ ? (...). Um país que não paga salários dignos a seus professores, que não os valoriza, acaba restringindo o desenvolvimento profissional, não tem como ser diferente" (P 19).

A sobrecarga de tarefas e a ausência de tempo para ler, preparar o material para as aulas, para buscar novas informações e para se apropriar de novos conhecimentos foram apresentadas como uma limitação para a realização de projetos que não fossem apenas de "fachada". Mas, nossos professores não tinham tempo para se preparar. $\mathrm{O}$ acúmulo de aulas e de atividades realizadas foi exaustivamente lembrado pelos entrevistados, como expressou o professor a seguir: "Eu sinto muita falta de ter um tempo para ler, para conhecer artigos novos, para ler novos autores. O tempo que sobra das aulas eu tenho que corrigir provas, preparar uma aula. Não dá para fazer mais nada além disso" (P 16).

Almeida (2006), ao analisar os dados relativos a uma pesquisa realizada com professores da rede municipal de São Paulo, apontou que, naquele contexto, a ausência de tempo para o preparo das aulas e para os encontros coletivos também foi uma reclamação marcante dos docentes. Para a autora, isso foi preocupante, pois era o tempo que estruturava e direcionava o trabalho docente. A escassez de tempo e seu controle levaram a uma situação de fragilidade do trabalho, pois o pouco tempo disponível pelos professores passou a ser utilizado na realização de tarefas determinadas externamente: "Cada vez mais o tempo é escasso e as instâncias administrativas, na busca da racionalidade da escola, tendem a con- 
trolá-lo, induzindo os professores a utilizá-los para realizar as tarefas estabelecidas centralmente, em vez de empregá-lo para satisfazer suas necessidades e alcançar seus próprios objetivos (ALMEIDA, 2006, p. 97).

Assim, como organizar de forma diferenciada o espaço e as práticas escolares? Com que tempo? O tempo "livre" dos professores tem sido cada vez mais reduzido, pois eles, além da sobrecarga de tarefas, que envolveram desde preenchimento de fichas, participação nos conselhos, responsabilidade com a coordenação de salas até as atividades tradicionais da docência, acumulavam aulas e funções em diferentes redes de ensino, evidenciando mais uma característica das condições de trabalho adversas. No entanto, tudo isso foi ignorado na implantação das reformas educacionais que alteraram as atividades realizadas e assumidas pelas escolas, sem transformar a maneira como se estruturava o tempo da docência. Tempo esse necessário para que o professor investisse em sua formação e na melhoria de seu próprio trabalho.

Ainda sobre o tempo dos professores, Souza (2008) apontou que o trabalho docente poderia ser definido em torno de dois eixos, sendo um primeiro normativo, quantificado e realizado na escola, portanto, visível e remunerado e, um segundo eixo, não-codificado, realizado, normalmente, fora da escola, em casa, não-mensurável, e, por isso, pouco avaliado pelas pessoas e não-remunerado pelas redes de ensino. A análise dessa autora corroborou teoricamente os dados empíricos coletados na pesquisa, como, por exemplo, esta afirmação de um de nossos sujeitos: "A carga horária é cada vez maior e tanto o governo como as pessoas não consideram a necessidade do professor ter um tempo disponível e eu não estou falando em tempo para não fazer nada, pois eu penso assim, que quando aos domingos eu vou à banca de jornal e seleciono as minhas leituras para a quinzena ou quando eu vou à biblioteca e retiro um livro, eu estou trabalhando, é tempo de trabalho, é um tempo necessário, eu preciso ter esse tempo para me preparar, para me formar continuamente, mas isso não é reconhecido, não é valorizado" (P24).

A dificuldade dos professores em se apropriar de um conhecimento mais amplo, tanto em relação à ausência de tempo quanto de recursos financeiros que lhes permitissem exercer com maior facilidade seu papel em sala de aula, foi agravada também pelas condições impostas aos encontros coletivos realizados no interior das escolas. Esses encontros, realizados nas unidades de trabalho, mas fora do horário normal de aulas, 
definiram-se como trabalho previsto no estatuto e medido em horas, aliás, horas exíguas, consideradas as imensas exigências da docência (SOUZA, 2008). Além do pouco tempo destinado aos encontros coletivos, já havíamos registrado, em trabalho anterior (DIAS-DA-SILVA; FERNANDES, 2006), que as escolas paulistas conviviam com a itinerância dos professores secundários, que, para integralizarem uma jornada de trabalho, acumulavam aulas em escolas diferentes ou, para complementarem a renda, acumulavam aulas na rede privada ou municipal ${ }^{8}$.

Como organizar o trabalho coletivo para que os exigidos projetos saíssem a contento? Em que condições trabalhavam os professores? Algumas respostas dos entrevistados nos ofereceram as pistas para confirmar que o trabalho coletivo não era efetivado, fato acentuado pela própria estrutura da rede pública estadual paulista que trazia implicações para as atribuições de aulas e para a organização das reuniões semanais. A ausência do trabalho coletivo, justificada pelas condições de organização das escolas, foi apontada por $80 \%$ dos professores como uma grande dificuldade imposta pelas reformas atuais.

Dias-da-Silva (2001), baseada em dados obtidos a partir de pesquisa colaborativa desenvolvida em uma escola pública no final dos anos 1990, já apontava que as condições presentes nas escolas de periferia se constituíam em impeditivos para o fortalecimento do trabalho coletivo. Algumas condições - como as regras de atribuição, a fragmentação das disciplinas, os baixos salários que obrigavam o professor a pegar muitas aulas em lugares diferentes - ainda permanecem presentes na rede pública (independentemente de ser escola central ou periférica) e, mais do que isso, não houve, ao longo dos anos, preocupação dos formuladores de políticas públicas em alterar as circunstâncias que pudessem levar a melhorias nas condições de trabalho coletivo nas escolas?.

A ausência do trabalho coletivo dificultava, e muito, a realização dos exigidos projetos de trabalho, já que a sua realização pressupunha encontros contínuos entre os professores. Como desenvolver projetos adequadamente em escolas onde o coletivo tem "um professor chegando e o outro saindo na hora do HTPC" (P 4)? Ou, como afirmou outra professora, uma escola com "muitos coletivos": "Não tem um corpo articulado, então as coisas emperram. Não tem um coletivo, há poucos momentos em que se reúnem todos e nem aí o coordenador consegue fazer a articulação do coletivo" (P 5). Para Zibas (2005, p. 213), a itinerância dos pro- 
fessores poderia ser apresentada como um elemento que fragilizava os encontros coletivos e a realização dos projetos, além de dificultar a identificação dos professores com as instituições escolares, seus alunos e suas necessidades.

É fundamental lembrar que as críticas destinadas à maneira como o trabalho coletivo se organizava, bem como à realização de projetos, veio de professores considerados bem-sucedidos e efetivos na rede pública e que, portanto, deveriam ter melhores condições de trabalho. No entanto, mesmo quando o professor exercia a docência em uma única escola, ele convivia com outros professores que trabalhavam em duas, três ou quatro unidades escolares. Assim, a maior parte dos professores das escolas públicas paulistas sofria com a presença de vários horários de encontros pedagógicos que não podiam ser, portanto, considerados coletivos.

Em muitas escolas, além da itinerância, havia também a rotatividade dos professores, notadamente nas escolas de periferia, onde o número de professores OFAs ${ }^{10}$ era, muitas vezes, superior ao número de efetivos. Nessas escolas, as relações coletivas eram bastante frágeis, pois os docentes conviviam com os "professores delivery" (ARANHA, 2007) ou "professores-macacos" (DIAS-DA-SILVA, 2001), que "pulavam" de uma escola para outra para dar suas aulas, sendo, muitas vezes, requisitados via telefone. Os professores entrevistados não eram delivery, mas sofriam com a presença dos docentes eventuais nas escolas e, talvez por isso, $40 \%$ deles (é importante notar que a crítica mais acentuada aos colegas de trabalho veio dos professores com maior tempo de atuação no magistério) se referiram, nas entrevistas, às dificuldades em relação aos professores que "ficavam de passagem" nas escolas e que não seguiam as regras pactuadas pelo grupo, como expressou uma professora:"Os eventuais não participam do coletivo da escola. Para eles fica muito difícil ter uma visão do todo, o papel de cada um e o papel de todos para que as coisas caminhem bem. Eles não conhecem profundamente as coisas que foram combinadas e aí ele não compartilha das mesmas coisas (...)" (P 4).

Assim, como anteriormente apontado em Dias-da-Silva e Fernandes (2006), tem sido nesse contexto de trabalho que se exige das escolas a formação de equipes pedagógicas e a realização de seus projetos, pressupondo encontros de um coletivo docente marcado pela sobrecarga de tarefas, pela itinerância e pela rotatividade, condições que dificultam 
qualquer possibilidade de construção e partilha de trabalho coletivo. Muitos professores apontaram essas condições como aspectos que colocavam em risco a discussão e a continuidade dos projetos: "A própria equipe escolar muda muito todos os anos, sempre há professores chegando e saindo, a equipe nunca é a mesma. Se a escola tivesse um grupo coeso seria mais fácil" (P 17).

Sem um trabalho realmente coletivo, os projetos se transformavam, muitas vezes, em meras atividades de fachada. E, nesse caso, atividades que valiam "pontos" na administração gerencialista e performática. Assim, muitas escolas, para não serem rebaixadas financeiramente ou para que os professores individualmente não fossem penalizados no bônus mérito, realizavam seus chamados projetos de forma muito precária. A "projetocracia" (CORREIA; MATOS, 2001) ampliou o risco de as escolas abandonarem os conteúdos fundamentais para se dedicarem à realização de algo que não se sabia ao certo o que era. Assim, a pressão para a realização dos projetos, mesmo em condições adversas, levou as escolas a realizarem trabalhos de qualidade duvidosa. A preocupação passou a ser não mais a formação, mas a avaliação posterior a que a escola era submetida, mesmo quando a avaliação se preocupava mais com o espetáculo do que com o processo de ensino-aprendizagem.

Os professores foram praticamente unânimes em afirmar: "Tirou foto? Registrou? Então está bom!" (P 18). Uma professora expressou a difícil relação entre a escola e o papel do professor, que foi se perdendo: "Hoje em dia, eu digo que a preocupação, a política educacional está voltada ao marketing só, ao espetáculo, e a aprendizagem em si não vem acontecendo, vem apresentando muitos problemas. Isso é muito doloroso e me coloca diante de uma questão: o que estou fazendo aqui?" (P 12).

Notamos um sofrimento ético (CORREIA; MATOS, 2001) no trabalho realizado pelos professores. Esse sofrimento, a nosso ver, resultou da contradição a que os professores foram submetidos nas escolas em que trabalhavam. Essa contradição se agravou em função da existência de um "velho" sistema ético (calcado nas necessidades da escola), que passou a conviver, paralelamente, com um "novo" sistema ético baseado no individualismo, na produtividade e na performatividade (BALL, 2002; 2005). Para esse autor, a reforma fez com que os professores abrissem mão de suas crenças e compromissos autênticos a respeito do ato de ensi- 
nar, ensejando que eles passassem a conviver com dúvidas e questionamentos sobre o papel a ser realizado nas escolas, já que fazer corretamente o trabalho passou a significar sentir-se mal em relação ao que estava sendo proposto.

Dessa forma, não temos como negar: as reformas e suas medidas, particularmente a instituição do bônus, acarretaram alterações significativas no modo de ser professor. Lüdke e Boing (2004) afirmaram que as novas condições impostas aos professores fizeram desmoronar o ofício docente e desestruturaram o trabalho que anteriormente se ancorava na transmissão de valores e de maneiras de ser e de fazer. $\mathrm{Na}$ opinião dos professores (aproximadamente $80 \%$ dos entrevistados), era angustiante conviver com a contínua desvalorização da escola e do próprio trabalho.

$\mathrm{Na}$ "escola do espetáculo", não foi apenas a relação do professor com as práticas docentes que passou por transformações. A própria relação com a formação profissional enquanto necessidade contínua do ofício do professor também foi alterada pela perspectiva performática. A formação continuada dos professores foi apontada como mais um dos elementos da performatividade, pois os cursos realizados contavam "pontos" na evolução funcional, sendo quantificados e transformados, posteriormente, em "benefícios" financeiros, mesmo quando não acarretavam melhorias no trabalho realizado em sala de aula (até porque faltavam as condições necessárias para que os novos saberes fossem, de fato, transformados em novas e melhores práticas pedagógicas).

Ball (2005) apontou que a pedagogia influenciada pelos aspectos economicistas e gerenciais, tais como as avaliações e as análises que interferiam no pagamento relacionado ao desempenho, ampliavam a responsabilidade individual sobre o processo educacional, incutindo a performatividade na "alma" do professor. A performatividade levou os professores, já sobrecarregados com as tarefas cotidianas, a participarem de cursos de qualidade duvidosa, fossem eles oferecidos pelo próprio Estado ou até mesmo pagos pelos docentes com os baixos salários recebidos pelo trabalho nas escolas. Não havia nos documentos oficiais referências claras aos cursos que os professores deveriam frequentar e nem mesmo critérios sobre a validação dos títulos, mas, assim mesmo, a procura por certificados foi visível, pois eles asseguravam a progressão na carreira e, portanto, maior salário. Essa falta de clareza em relação aos critérios para a frequência nos cursos de formação continuada foi apontada por uma professora: 
“É uma progressão maluca (...). Não há clareza sobre o que conta e o que não conta e há risco até de não contar nada. O discurso é: 'você tem que se atualizar'. Tá certo. Mas em que condições? Nada parece que está funcionando"(P 3).

Os cursos ofertados pela rede estadual não foram valorizados pelos professores entrevistados. Prova disso foi o baixo número de entrevistados que se inscreveram nos programas oficiais de formação continuada. Apenas cinco professores, entre as três diretorias participantes da pesquisa, participaram desses cursos nos últimos tempos. Por outro lado, mais da metade dos professores entrevistados teceram críticas em relação à qualidade dos cursos e aos programas oferecidos pela rede estadual, assim como à competência dos professores responsáveis pela formação e o desconhecimento da realidade da escola pública por parte das instituições de ensino superior onde os cursos eram oferecidos: "Eles não conhecem a nossa realidade, eles não sabem com que tipo de aluno nós trabalhamos, eles são totalmente fora da realidade da escola. Então fazer um curso desses para quê? Eu só fui um dia e não voltei mais" (P 22).

O trabalho docente, marcado pela sobrecarga de tarefas, pela ampliação das responsabilidades sociais, pelos baixos salários e o acúmulo de aulas, entre outras coisas, sofria, ainda, com a cobrança da participação em cursos realizados nos poucos horários livres que os professores deveriam destinar à família e à própria formação cultural. Os cursos oferecidos pela rede estadual ocorriam, normalmente, aos sábados, e isso também foi alvo de críticas por parte dos professores: “ No sábado é o dia que eu consigo pesquisar alguma coisa na Internet, consigo ler um jornal, consigo pôr minimamente a minha vida em ordem, minha família, meus filhos. Não dá para imaginar, depois de uma semana de trabalho desgastante, o profissional ficar o sábado todo em um curso" (P 24).

As críticas aos cursos oferecidos pela rede estadual e à presença de mecanismos de pressão e cobrança que forçavam a participação dos docentes foram evidentes nas falas dos professores. No entanto, podemos afirmar que os professores entrevistados tinham uma trajetória marcada pelo estudo e demonstraram ter compromisso com a própria formação. No entanto, eles rejeitavam a obrigatoriedade, as convocações e os cursos aos finais de semana, que, longe de atenderem as necessidades da escola atual, faziam parte da lógica absurda da performatividade. A formação, vista sob a perspectiva da performatividade, levou à assunção do indivi- 
dualismo, o que não contribuiu para o desenvolvimento das escolas a partir do trabalho coletivo. Nesse sentido, Cunha (1999, p. 134) afirmou que "a responsabilidade da formação continuada se dá de forma cumulativa e individual, incentivando-se para que cada um faça seus cursos e sua carreira, idéia que dificilmente coabita com uma profissionalidade solidária, em que o projeto educativo do espaço de atuação seja o núcleo do próprio aperfeiçoamento pessoal".

Além das críticas aos programas e projetos de formação postos em prática pelas reformas educacionais, os professores também reivindicaram mudanças nas condições de trabalho para que pudessem se dedicar plenamente às atividades docentes, incluindo as atividades de formação que são inerentes à prática profissional. "Eu tenho dois cargos, dou quase sessenta aulas por semana, em que horas que eu vou estudar?", questionou uma professora.

Nesse sentido, a escola performática, que se disseminou nos últimos anos e ainda apresenta grande força na rede paulista, somente será capaz de oferecer um ensino de qualidade para todos se considerar a necessidade de mudanças nas condições de trabalho dos professores. Caso contrário, as reformas educacionais continuarão apenas a condicionar novas práticas apoiadas na racionalidade econômica, que modificam a organização do trabalho, mas são incapazes de melhorar qualitativamente o ensinar e aprender, fazendo de nossas escolas apenas um local de "espetáculo". Independentemente do local de trabalho, os professores entrevistados mostraram-se profundamente incomodados com a atual situação das escolas públicas estaduais paulistas. A análise serena e carregada de saberes nos permitiu interpretar como as reformas têm se manifestado no interior das escolas, as reações dos docentes perante as mudanças e elaborar um panorama geral das escolas situadas em uma ampla região do interior paulista. 


\section{Referências}

ALMEIDA, M. I. A reconstrução da profissionalidade docente no contexto das reformas educacionais - vozes dos professores na escola ciclada. In: SILVA, A. M. M. et al (Orgs.). Políticas educacionais, tecnologias e formação do educador: repercussões sobre a didática e as práticas de ensino. Recife: Endipe, 2006. p. 83-107.

ARANHA,W. L. A. Professores eventuais nas escolas estaduais paulistas: ajudantes de serviço geral da educação?. 2007. 102 f. Dissertação (Mestrado em Educação Escolar). Faculdade de Ciências e Letras, Universidade Estadual Paulista, Araraquara, 2007.

ASSUNÇÃO, A. A. Saúde e condições de trabalho nas escolas públicas. In: OLIVEIRA, D. A. (Org.). Reformas educacionais na América e os trabalbadores docentes. Belo Horizonte: Autêntica, 2003, p. 87-102.

BALL, S. J. Reformar escolas/reformar professores e os terrores da performatividade. Revista Portuguesa de Educação, Braga, v. 15, n. 2, p. 3-23, 2002.

BALL, S. J. Performatividade, privatização e o pós-Estado do bem estar. Educação e Sociedade, Campinas, v. 25, p. 1105-1126, Set/Dez 2004.

BALL, S. J. Profissionalismo, gerencialismo e performatividade. Cadernos de Pesquisa, São Paulo, v. 35, p. 539-564, Set./Dez. 2005.

BARROSO, J. O Estado e a educação: a regulação transnacional, a regulação nacional e a regulação local. In: BARROSO, J. (Org.). A regulação das políticas públicas de educação: espaços, dinâmicas e actores. Lisboa: Educa, 2006, p. 41-70.

BIRGIN, A. Novas regulações do trabalho docente: o caso da reforma argentina. Cadernos de Pesquisa, São Paulo, 111, p. 95-113, dez/2000.

CODO, W. et al. Burnout: sofrimento psíquico dos trabalhadores em educação. Cadernos de Saúde. São Paulo: CUT, v. 14, p. 53, 2000.

CORREIA, J. A.; MATOS, M. Solidões e solidariedades nos quotidianos dos professores. Porto: ASA, 2001, p. 191-214.

CUNHA, M. I. Profissionalização docente: contradições e perspectivas. In: VEIGA, I.

P. A.; CUNHA, M. I. (Orgs.). Desmistificando a profissionalização do magistério. Campinas: Papirus, 1999. p. 127-147.

DIAS-DA-SILVA, M. H. G. F. Projeto pedagógico e escola de periferia: sonho ou pesadelo. In: Reunião Anual da Associação Nacional de Pós-Graduação e Pesquisa em Educação, 24., 2001, Caxambu. Reuniões Anuais...Caxambu: ANPED, 2001. Trabalho disponível em: <http://www.anped.org.br/inicio>. Acesso em: 20 jun. 2007.

DIAS-DA-SILVA, M. H. G. F.; LOURENCETTI. G. C. A 'voz' dos professores e algumas reformas educacionais nas séries finais do ensino fundamental: desenvolvimento ou impasse? In: SAMPAIO, M. M. F. O cotidiano escolar face às politicas educacionais. Araraquara: JM, 2002. p. 21-43.

DIAS-DA-SILVA, M. H. G. F; FERNANDES, M. J. S. As condições de trabalho dos professores e o trabalho coletivo: mais uma armadilha das reformas educacionais neoliberais? Seminário da Redestrado, VI, 2006. Anais eletrônicos... Rio de Janeiro, 2006. Trabalho disponível em: <http://www.fae.ufmg.br/estrado/cd_viseminario/programação.htm>. Acesso em: 20 jun. 2007.

ESTEVE, J. M. O mal-estar docente: a sala de aula e a saúde dos professores. Bauru: EDUSC, 1999.

FALSARELLA, A. M. Políticas de capacitação e mudanças no cotidiano escolar. In: 
SAMPAIO, M. M. F. (Org.). O cotidiano escolar face às políticas educacionais. Araraquara: JM, 2002. p. 69-94.

GUILHERME, C. C. F. A progressão continuada e a inteligência dos professores. 2002, $143 \mathrm{f}$. Tese (Doutorado em Educação Escolar) - Faculdade de Ciências e Letras, Universidade Estadual Paulista, Araraquara.

LOURENCETTI, G. C. Mudanças sociais e reformas educacionais: repercussões no trabalho docente. 2004.161f. Tese (Doutorado em Educação Escolar). Faculdade de Ciências e Letras, Universidade Estadual Paulista, Araraquara, 2004.

LÜDKE, M.; BOING, L. A. Caminhos da profissão e da profissionalidade docente. Educação e Sociedade, Campinas, v. 25, p. 1159-1180, Set/Dez 2004.

MARIN, A. J. Educação continuada: introdução a uma análise de termos e concepções. Cadernos CEDES. Campinas, n. 36, p. 13-20, 1995.

MARIN, A. J.; GUARNIEIRI, M. R. Escola Fundamental, ações de inovação e desenvolvimento profissional de professoras: focalizando as "salas-ambiente". In: SAMPAIO, M. M. F. O cotidiano escolar face às políticas educacionais. Araraquara: JM, 2002. p. 47-65.

MARTINS, A. M. A autonomia outorgada: uma avaliação da política educacional no Estado de São Paulo (1995-1999). Ensaio: avaliação políticas públicas educacionais, Rio de Janeiro, v. 9, n. 33, p. 415-442, Out/Dez 2001.

MORAES, M. C. M. Recuo da teoria. In: MORAES, M. C. M. (Org.). Iluminismo às avessas: produção de conhecimento e políticas de formação docente. Rio de Janeiro: DP\&A, 2003, p. 151-167.

OLIVEIRA, D. A. As reformas educacionais e suas repercussões sobre o trabalho docente. In: OLIVEIRA, D.A. (Org.) Reformas educacionais na América Latina e os trabalhadores docentes. Belo Horizonte: Autêntica, 2003, p 13-35.

OLIVEIRA, D. A. A Reestruturação do trabalho docente: precarização e flexibilização. Educação e Sociedade, Campinas, v. 25, p. 1127-1144, Set/Dez 2004.

OLIVEIRA, D. A. El trabajo docente y la nueva regulación educativa en América Latina. In: FELDFEBER, M.; OLIVEIRA, D. A. (Comps.). Politicas educativas y trabajo docente: nuevas regulaciones, nuevos sujetos? Buenos Aires: Noveduc, 2006 (a), p. 17-31.

PEREIRA, J. B. B. A escola secundária numa sociedade em mudança: interpretação sócioantropológica de uma experiência administrativa. São Paulo: Pioneira, 1969.

SAMPAIO, M. M.; MARIN, A. J. Precarização do trabalho docente e seus efeitos sobre as práticas curriculares. Educação e Sociedade, Campinas, v. 25, p. 1203-1226, Set/Dez 2004. SANTOS, L. L. C. P. Formação de professores na cultura do desempenho. Educação e Sociedade, Campinas, v. 25, p. 1145-1158, Set/Dez 2004.

SÃO PAULO (Estado). Secretaria de Estado da Educação. A escola de cara nova, SP, 1996. SHIROMA, E. O.; CAMPOS, R. F. La resignificación de la democracia escolar mediante el discurso gerencial: liderazgo, gestión democrática y gestión participativa. In: FELDFEBER, M.; OLIVEIRA, D. A. (Comps.). Políticas educativas y trabajo docente: nuevas regulaciones, nuevos sujetos? Buenos Aires: Noveduc, 2006, p. 221-237.

SHIROMA, E. O.; EVANGELISTA, O. Profissionalização como estratégia de gerenciamento de professores. Revista de Estudos Curriculares, Braga, n. 2, 2003.

SOUZA, A. N. Condições de trabalho na carreira docente: comparação Brasil-França. Seminário da Redestrado, VII, 2008. Anais eletrônicos... Buenos Aires, 2008. Trabalho disponível em: <http://www.fae.ufmg.br/estrado/cd_viiseminario/programação.htm>. 
Acesso em: 10 set. 2008.

ZIBAS, D. M. L. Un juego de espejos rotos? La vida escolar cotidiana y las políticas educativas en América Latina. Revista Ibero-Americana de Educación, OEI, 1997 n. 15, p. 121 137.

ZIBAS, D. M. L. A reforma do Ensino Médio no Ceará e suas contradições. Cadernos de Pesquisa, São Paulo, v. 35, n. 201-226, p. 201-226, Jan./Abr. 2005.

\section{Notas}

1 Baseada na reforma do Estado proposta por Bresser Pereira, o governo paulista, representado inicialmente por Mario Covas, implementou uma série de mudanças nos âmbitos institucional, cultural e de gestão. Entre as medidas decorrentes do "choque de gestão" estavam o enxugamento do Estado, a restrição dos gastos públicos, a exaltação da responsabilidade individual e o saneamento das contas públicas.

2 A década de 1980 foi fundamental para a educação paulista. Em um período pós-ditadura militar, ocorreram tentativas de democratização do ensino e de participação efetiva da comunidade nas decisões escolares. As eleições diretas culminaram com o governo de Franco Montoro, que, atendendo as reivindicações docentes, favoreceu a discussão e a aprovação de um novo Estatuto do Magistério e a elaboração coletiva de propostas curriculares para as escolas estaduais.

3 Para Marin (1995, p. 17), o termo capacitação pode revelar-se de duas formas. A primeira está relacionada ao fato de tornar-se capaz, habilitar, e a segunda, como maneira de convencimento e persuasão. Nas ações desenvolvidas pelas teleconferências realizadas nesse período, percebia-se claramente a intenção de persuadir e convencer os professores, tornando-os adeptos das ideias defendidas pela Secretaria. Elas visavam à defesa de um ideário que deveria ser aceito acriticamente pelos professores, em nome da melhoria e da inovação. As teleconferências, modalidade nova naquele momento, dificultavam a análise e a crítica racional das reformas.

4 Optamos por manter o discurso dos professores, mesmo quando eles destoam da norma culta da Língua Portuguesa.

5 O número corresponde à ordem de participação do professor nas entrevistas.

6 É importante ressaltar que não havia nenhuma questão específica sobre o bônus. Assim, o incômodo dos professores com tal mecanismo surgiu naturalmente nas entrevistas.

$7 \mathrm{Na}$ rede estadual paulista, havia projetos elaborados pelas escolas que eram, normalmente, em número elevado (encontramos até trinta projetos a serem desenvolvidos), havia os projetos elaborados pelas equipes pedagógicas das Diretorias de Ensino e, ainda, os da Secretaria da Educação. Não havia uma organicidade nos projetos desenvolvidos e nem mesmo um número definido de ações, o que demonstrava a precariedade dos planejamentos intra e extraescolar.

8 Encontramos entre os entrevistados sete casos de professores que acumulavam cargos e funções e que trabalhavam, em média, 60 horas semanais. 
9 Algumas condições de trabalho adversas são históricas na rede pública paulista, notadamente a questão da itinerância, da rotatividade dos professores e a busca por trabalho em escolas mais prestigiadas do ponto de vista social e distantes das áreas periféricas. Tais problemas já eram apontados por Pereira (1969), em pesquisa realizada na década de 1960, na região metropolitana de São Paulo.

10 OFAs - Ocupantes de Função Atividade -, professores contratados temporariamente. Segundo dados da própria Secretaria, há, atualmente, na rede pública estadual paulista, aproximadamente $50 \%$ de professores contratados temporariamente, portanto, professores que trabalham de forma precarizada.

Recebido: 23/06/2009

Aprovado: 30/06/2010

Contato:

Universidade Estadual Paulista Júlio de Mesquita Filho

Faculdade de Ciências de Bauru Departamento de Educação Av. Eng ${ }^{\circ}$ Luiz Edmundo Carrijo Coube $s / n$ Vargem Limpa - Bauru - SP CEP 17033-360 
